A) Check for updates

Cite this: Dalton Trans., 2020, 49, 858

Received 3rd December 2019, Accepted 10th December 2019

DOI: $10.1039 / c 9 d t 04618 f$

rsc.li/dalton

\section{The reactivity of molecular oxygen and reactive oxygen species with [FeFe] hydrogenase biomimetics: reversibility and the role of the second coordination sphere $\dagger$}

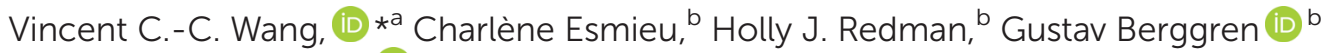 \\ and Leif Hammarström (D) *a
}

\begin{abstract}
The development of oxygen-tolerant $\mathrm{H}_{2}$-evolving catalysts plays a vital role for a future $\mathrm{H}_{2}$ economy. For example, the [FeFe] hydrogenase enzymes are excellent catalyst for $\mathrm{H}_{2}$ evolution but rapidly become inactivated in the presence of $\mathrm{O}_{2}$. The mechanistic details of the enzyme's inactivation by molecular oxygen still remain unclear. Here, two $\mathrm{H}_{2}$-evolving diiron complexes $\left[\mathrm{Fe}_{2}\left(\mu-\mathrm{SCH}_{2} \mathrm{NHCH}_{2} \mathrm{~S}\right)(\mathrm{CO})_{6}\right]\left(1^{\text {adt }}\right)$ and $\left[\mathrm{Fe}_{2}\left(\mu-\mathrm{SCH}_{2} \mathrm{CH}_{2} \mathrm{CH}_{2} \mathrm{~S}\right)(\mathrm{CO})_{6}\right]\left(2^{\text {pdt }}\right)$, inspired by the active site of [FeFe] hydrogenase, were investigated for their reactivity with molecular oxygen and reactive oxygen species. A one-electron reduced and oxygenated $\mathbf{1}^{\text {adt }}$ species was identified and characterized spectroscopically, which can be directly generated by reacting with molecular oxygen and chemical reductants at room temperature but it is unstable and gradually decomposes. Interestingly, the whole process is reversible and the addition of protons can facilitate the deoxygenation process and prevent further degradation at room temperature. This new identification of intermediate species serves as a model for studying the reversible inactivation and degradation of oxygen-sensitive [FeFe] hydrogenases by $\mathrm{O}_{2}$, and provides chemical precedence for such processes. In comparison, the complex lacking the nitrogen bridgehead, $2^{\text {pdt }}$, exhibits reduced reactivity towards $\mathrm{O}_{2}$ in the presence of reductants, highlighting that the importance of the second coordination sphere on modulating the oxygenation processes. These results provide new directions to design molecular electrocatalysts for proton reduction operated at ambient conditions and the re-engineering of [FeFe] hydrogenases for improving oxygen tolerance.
\end{abstract}

\section{Introduction}

In the past decade, the development of noble-metal-free complexes for $\mathrm{H}_{2}$ evolution has been a very active research field. A variety of metal complexes inspired by hydrogenases, both functional $^{1}$ or structural ${ }^{2}$ mimics, has been prepared to generate synthetic catalysts for $\mathrm{H}^{+} / \mathrm{H}_{2}$ interconversion and to understand key feature for catalysis. However, most of these molecular complexes are oxygen-sensitive under catalytic turnover conditions. For example, Ni-bis(diphosphine) complexes developed by the Dubois group ${ }^{3,4}$ and diiron complexes based on the active site of [FeFe] hydrogenases, ${ }^{5,6}$ have been shown to

\footnotetext{
${ }^{a}$ Program of Physical Chemistry, Department of Chemistry - Ångström Laboratory, Uppsala University, Uppsala 75120, Sweden.E-mail: leif.hammarstrom@kemi.uu.se ${ }^{b}$ Program of Molecular Biomimetics, Department of Chemistry - Ångström Laboratory, Uppsala University, Uppsala 75120, Sweden

$\dagger$ Electronic supplementary information (ESI) available: Detailed experimental procedures and further spectroscopic and mechanistic studies. See DOI: 10.1039/c9dt04618f
}

be incompatible with air-operated conditions. Therefore, it is important to understand the damage processes by molecular oxygen during $\mathrm{H}_{2}$ evolution, in order to provide new ideas for re-engineering of catalysts to achieve improved oxygen-tolerance. To gain further insight into this chemistry, we have probed two biomimetic molecular electrocatalysts, $\mathrm{Fe}_{2}(\mathrm{adt})$ $(\mathrm{CO})_{6}($ adt $=$ azadithiolate $), \mathbf{1}^{\text {adt }}$ and $\mathrm{Fe}_{2}(\mathrm{pdt})(\mathrm{CO})_{6}($ pdt $=$ propanedithiolate), $2^{\text {pdt }}$ (Fig. 1), ${ }^{5-9}$ and investigated their reactivity with molecular oxygen. Both complexes are structurally similar to the diiron subsite of the catalytic cofactor of oxygen-sensitive $[\mathrm{FeFe}]$ hydrogenases (the "H-cluster" as shown in Fig. 1). ${ }^{10-13}$ However, they differ in the nature of the bridgehead atom in the dithiolato ligand, and thus provide insight into the influence of proton relays for the reactivity of the low valence metal center towards $\mathrm{O}_{2}$.

The reactivity of analogues of $\mathbf{1}^{\text {adt }}$ and $2^{\text {pdt }}$ towards $\mathrm{O}_{2}$ under electrocatalytic conditions has previously been reported. ${ }^{5,6}$ However, under such conditions, it is challenging to characterize the true species that attack molecular catalysts and the corresponding engaged state from catalysts. For 


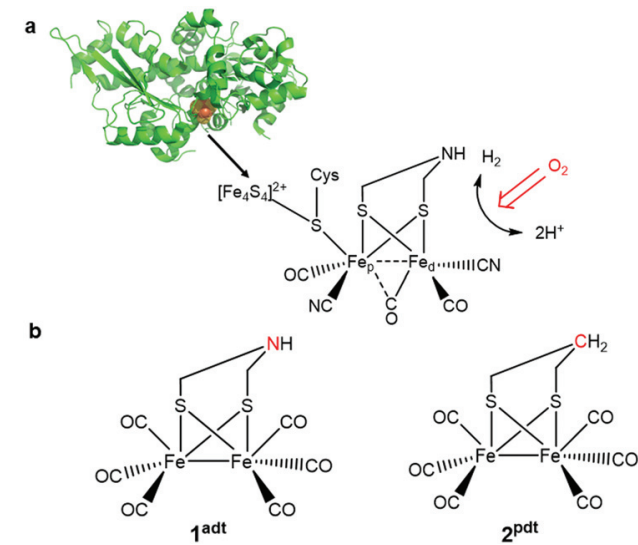

Fig. 1 (a) A schematic representation of the [FeFe] hydrogenase from Chlamydomonas reinhardtii ( $\mathrm{Cr}$ HydA1, PDBID: 3LX4) and the H-cluster. (b) The two biomimetic complexes, $1^{\text {adt }}$ and $2^{\text {pdt }}$, used to investigate reactivity towards $\mathrm{O}_{2}$ and ROS.

example, a variety of reactive oxygen species (ROS) can be generated directly from the electrode as suggested in eqn (1)-(3) before proton reduction reaction takes place (eqn (4) and Fig. S1†).

$$
\begin{array}{ccc}
\mathrm{O}_{2}+2 \mathrm{e}^{-}+2 \mathrm{H}^{+} \rightleftharpoons \mathrm{H}_{2} \mathrm{O}_{2} & E=0.28 \mathrm{~V} & (1) \\
\mathrm{O}_{2}+\mathrm{e}^{-}+\mathrm{H}^{+} \rightleftharpoons \mathrm{HO}_{2} & E=-0.05 \mathrm{~V} & (2) \\
\mathrm{O}_{2}+\mathrm{e}^{-} \rightleftharpoons \mathrm{O}_{2}^{\cdot-} & E=-0.33 \mathrm{~V} & (3) \\
2 \mathrm{H}^{+}+2 \mathrm{e}^{-} \underset{\mathrm{V} \text { vs. standard hydrogen electrode }}{\rightleftharpoons} \mathrm{H}_{2} & E=7
\end{array} \quad \text { (4) }
$$

Herein, we report on spectroscopic investigations of the reactivity of these two complexes towards molecular oxygen. More specifically, the distinct vibrational absorption bands for carbonyl groups $\left(\nu_{\mathrm{CO}}\right)$ from $\mathbf{1}^{\text {adt }}$ and $2^{\text {pdt }}$ allow to monitor changes in the electronic and geometric structure of the diiron center by IR spectroscopy. Chemical reductants were employed to address the influence of the redox states on the reaction. This alternative approach enabled the generation of one-electron reduced and oxygenated $\mathbf{1}^{\text {adt }}$ and $2^{\text {pdt }}$ by adding $\mathrm{O}_{2}$ in combination with reductants that have a more positive reduction potential than those of the respective diiron complexes $\left(\mathrm{Fe}^{\mathrm{I}} \mathrm{Fe}^{\mathrm{I}} / \mathrm{Fe}^{\mathrm{I}} \mathrm{Fe}^{0}\right)$. The whole process for $\mathbf{1}^{\text {adt }}$ is reversible, although the reduced and oxygenated species is unstable at room temperature. The addition of protons prevents further damage and facilitates the deoxygenation process to regenerate the starting material. The chemical process may be biologically relevant to the reactivity of [FeFe] hydrogenase towards molecular oxygen and represent a general oxygenation and reactivation scheme for this class of complexes.

\section{Results and discussion}

\section{Reactivity of $1^{\text {adt }}$ and $2^{\text {pdt }}$ towards $\mathrm{O}_{2}$ under reducing conditions}

The reactivity of $\mathbf{1}^{\text {adt }}$ and $\mathbf{2}^{\text {pdt }}$ with molecular oxygen was probed in the absence and presence of chemical reductants, i.e. bis(benzene)chromium $\left(\mathrm{Cr}(\mathrm{bz})_{2}\right)$, cobaltocene $\left(\mathrm{CoCp}_{2}\right)$ and bis(pentamethylcyclopentadienyl)cobalt $\left(\mathrm{CoCp}_{2}{ }^{*}\right)$. The reduction potential for these reductants are respectively $E=-1.15 \mathrm{~V}$ (all potentials reported herein are against $\mathrm{Fc} / \mathrm{Fc}^{+}$), $E=-1.33 \mathrm{~V}$ and $E=-1.94 \mathrm{~V}$, compared to the reduction potential of $-1.6 \mathrm{~V}$ for $1^{\text {adt }}$ and $2^{\text {pdt }}$ (Fig. S1 and Table S1 $\dagger$ ). Recently, some reductants, such as $\mathrm{CoCp}_{2}$ and $\mathrm{CoCp}_{2}{ }^{*}$ have been applied to study $\mathrm{H}_{2}$ evolving mechanism with related diiron complexes via transient spectroscopy. ${ }^{14,15}$ As expected in light of their respective reduction potentials, $\mathbf{1}^{\text {adt }}$ and $2^{\text {pdt }}$ did not react with $\mathrm{CoCp}_{2}$, $\mathrm{Cr}(\mathrm{bz})_{2}$ or molecular oxygen in isolation. Upon addition of the chemical reductants or purging with $\mathrm{O}_{2}$, the IR spectra featured $\nu_{\mathrm{CO}}$ bands of $1^{\text {adt }}$ and $2^{\text {pdt }}$ at 2074, 2033, 2000 and $1989 \mathrm{~cm}^{-1}$, which are indiscernible from the starting material (Fig. 2). In comparison, multiple new $\nu_{\mathrm{CO}}$ bands from the two

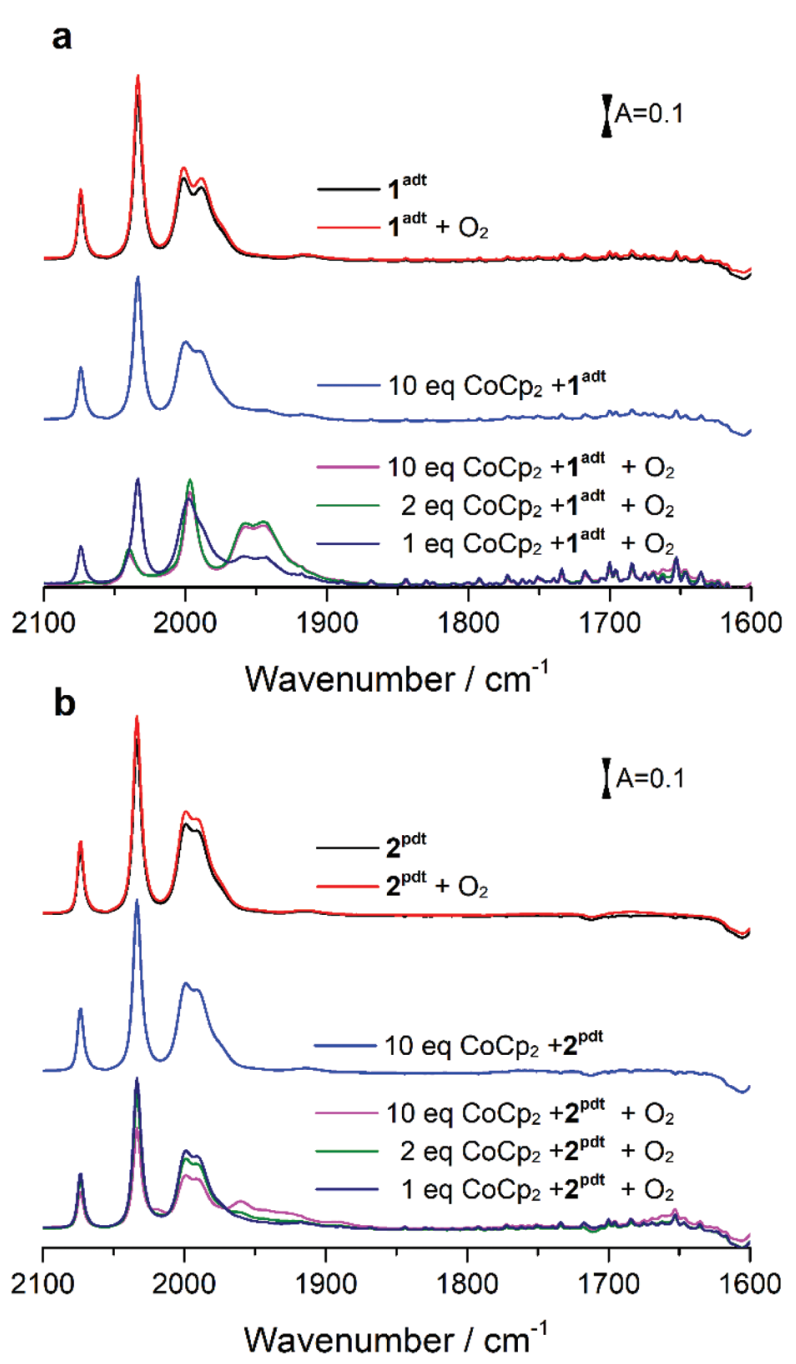

Fig. 2 Infrared spectra obtained from a mixture of $1^{\text {adt }}$ (a) (or $2^{\text {pdt }}$ (b)) and cobaltocene upon exposure to the excess of $\mathrm{O}_{2}$. The complex $1^{\text {adt }}$ $(0.5 \mathrm{mM})$ or $2^{\text {pdt }}(0.5 \mathrm{mM})$ was mixed with different equivalents of $\mathrm{CoCp} \mathrm{p}_{2}$ first and then molecular oxygen was added to a mixture solution. The intensity of red line is stronger than that of black line because solvent (dichloromethane, DCM) was purged away by $\mathrm{O}_{2}$ during the reaction. 
Fe complexes were observed at lower wavenumbers, between $1970 \mathrm{~cm}^{-1}$ and $1850 \mathrm{~cm}^{-1}$ (Fig. S2†), when mixing with the stronger reducing agent, $\mathrm{CoCp}_{2}{ }^{*}$. These features indicate the dimerization of one-electron reduced $\mathbf{1}^{\text {adt }}$ or $2^{\text {pdt }}$ species as reported from earlier studies. ${ }^{16}$

Unexpectedly, we noticed that two new peaks at 1957 and $1946 \mathrm{~cm}^{-1}$ appeared when a mixture of $\mathrm{CoCp}_{2}$ and $\mathbf{1}^{\text {adt }}$ was exposed to air under ambient conditions. When mixing more than two equivalents of $\mathrm{CoCp}_{2}$ (or $\mathrm{Cr}(\mathrm{bz})_{2}$ ) and $\mathbf{1}^{\text {adt }}$ with excess $\mathrm{O}_{2}$, the four bands attributed to $\mathbf{1}^{\text {adt }}$ almost disappeared and four new distinct bands for $\nu_{\mathrm{CO}}$ were observed at lower wavenumbers, 2038, 1997, 1957 and $1946 \mathrm{~cm}^{-1}$ as shown in Fig. 2a and 3. This new spectrum is distinctly different from one-electron reduced species of $\mathbf{1}^{\text {adt }}$ reported before (Table S2 $\dagger$ ). Still, the red-shift of the four bands by $c a .35-45 \mathrm{~cm}^{-1}$ relative to the starting material $\mathbf{1}^{\text {adt }}$ suggests that the newly formed species is reduced. In control experiments, no new peaks were observed when adding oxygen-free DI water (Fig. S3 $\dagger$ ) to a mixture of $\mathrm{CoCp}_{2}$ and $\mathbf{1}^{\text {adt }}$ (or $2^{\text {pdt }}$ ), which exclude the formation of a protonated and reduced species. In comparison, a mixture of $2^{\text {pdt }}$ and $\mathrm{CoCp}_{2}$ exhibited less reactivity toward $\mathrm{O}_{2}$. Still, new bands for $\nu_{\mathrm{CO}}$ were observed at 2020, 1960 and $1891 \mathrm{~cm}^{-1}$ and a broad shoulder peak spanned between 1950 and $1910 \mathrm{~cm}^{-1}$ (Fig. 2b). The multiple number of new and broad peaks from $2^{\text {pdt }}$ suggest at least two different species coexist after reacting a mixture of $\mathrm{CoCp}_{2}$ and $2^{\text {pdt }}$ with $\mathrm{O}_{2}$ and likely dimerization occurred comparing to IR spectra from mixing $\mathrm{CoCp}_{2}{ }^{*}$ and $2^{\text {pdt }}$. In both cases, black precipitates were observed after introducing $\mathrm{O}_{2}$ into a mixture of reductants and $\mathbf{1}^{\text {adt }}$ or $2^{\text {pdt }}$. These precipitates were also observed when adding $\mathrm{O}_{2}$ to a solution containing only $\mathrm{CoCp}_{2}$, and were thus not analyzed in detail. The newly formed IR bands from these new species gradually decayed in ca. 20 minutes under anaerobic conditions, indicating that they were unstable at room temperature. Critically, the $\nu_{\mathrm{CO}}$ bands for as-prepared $\mathbf{1}^{\text {adt }}$ were partially recovered again, while full degradation occurred for the new species generated from $2^{\text {pdt }}$ (vide infra and Fig. S18†). Thus, distinct differences were observed between $2^{\text {pdt }}$ and the more biologically relevant $\mathbf{1}^{\text {adt }}$. The latter revealed not only a more defined product in the reaction with $\mathrm{O}_{2}$, with only four distinct new $\nu_{\mathrm{CO}}$ peaks, but also showed a high degree of reversibility, as compared to mixed products and irreversibility observed for $2^{\text {pdt }}$.

\section{Spectroscopic characterization of transient species}

The minute-scale lifetime of the transient species at room temperature allowed for a more detailed spectroscopic characterization to explore its geometric and electronic structure. The resulting product directly obtained by reacting a mixture of $1^{\text {adt }}$ and $\mathrm{Co}(\mathrm{Cp})_{2}$ (or $\mathrm{Cr}(\mathrm{bz})_{2}$ ) with $\mathrm{O}_{2}$ showed a mass peak at $\mathrm{m} / \mathrm{z} 401.76 \mathrm{amu}$, detected by electron-spray mass spectroscopy, assigned to $\left[\mathrm{O}+\mathbf{1}^{\text {adt }}-\mathrm{H}\right]$, indicated that an oxygenated species, $\mathbf{0 - 1} \mathbf{1}^{\text {adt- }}$ was formed (Fig. S4 and S5 $\dagger$ ). Indeed, a shift of two amu units for $\mathbf{O}-\mathbf{1}^{\text {adt- }}$ was observed when ${ }^{18} \mathrm{O}_{2}$ was introduced to a mixture of $\mathrm{CoCp}_{2}$ and $\mathbf{1}^{\text {adt }}$ (Fig. S6 $\dagger$ ). Similarly, a mass peak for $\left[\mathrm{O}+2^{\text {pdt- }}\right]$ at 402.6 amu was also observed (Fig. S7†). Earlier work conducted by Darensbourg and co- workers has demonstrated that meta-chloroperoxybenzoic acid (mCPBA) can oxygenate $2^{\text {pdt }}$ to generate a mono-oxygenated $2^{\text {pdt }}\left(\mathbf{O}-2^{\text {pdt }}\right)$, through an oxygen atom transfer reaction to a thiol ligand of $2^{\text {pdt }} \cdot{ }^{17}$ Consequently, we explored the possibility of the oxygen atom binding to a $S$ atom of $\mathbf{1}^{\text {adt }}$ as well. Indeed, an IR band assigned to $\nu_{\mathrm{S}=\mathrm{O}}$ from $\mathbf{0}-\mathbf{1}^{\text {adt- }}$ was observed at $1030 \mathrm{~cm}^{-1}$ and the peak displayed the expected isotope shift to $993 \mathrm{~cm}^{-1}$ when ${ }^{18} \mathrm{O}_{2}$ was used in the oxygenation reaction (Fig. 4). The IR bands assigned to $\nu_{\mathrm{S}=\mathrm{O}}$ are in excellent agreement with the DFT-simulated IR spectrum $\left(1028 \mathrm{~cm}^{-1}\right.$ for ${ }^{16} \mathrm{O}$ and $996 \mathrm{~cm}^{-1}$ for ${ }^{18} \mathrm{O}$ ) for a one-electron reduced and oxygenated species featuring an oxygenated thiol group $(\mathrm{S}=\mathrm{O})$ (Fig. 4c). Noticeably, these two peaks disappeared in ca. 25 minutes, which is in line with the disappearance of the $1946 \mathrm{~cm}^{-1}\left(\nu_{\mathrm{CO}}\right)$ peak assigned to $\mathbf{O}^{\text {- }}{ }^{\text {adt- }}$ (Fig. S17†).

To characterize the electronic structure of $\mathbf{0 - 1}{ }^{\text {adt- }}$, electron paramagnetic resonance (EPR) spectroscopy was employed. A new EPR signal for $\mathbf{O}-\mathbf{1}^{\text {adt- }}$ was observed at $g \sim 2.14$ and 2.02 compared to EPR-silent $\mathbf{1}^{\text {adt }}$, confirming that $\mathbf{O - 1} \mathbf{1}^{\text {adt- }}$ is a oneelectron reduced species. Spin quantification of the double integral spectrum using Cu-EDTA as a standard, suggested that $50 \%$ of the initial $\mathbf{1}^{\text {adt }}$ complex converted to this one-electron reduced species (Fig. S8 $\dagger$ ). In the case of $2^{\text {pdt }}$, the yield of the oxygenated reduced species was limited to $c a$. $30 \%$. The formation of $\mathbf{O}-\mathbf{1}^{\text {adt- }}$ also results in the appearance of a new absorption peak at $605 \mathrm{~nm}$ in the UV-visible spectrum (Fig. S9a $\dagger$ ). In contrast, $\mathbf{1}^{\text {adt- }}$ shows absorption bands around 560 and $700 \mathrm{~nm} .{ }^{14,15}$ As this new signal at $605 \mathrm{~nm}$ disappears with a half-life time $\left(t_{1 / 2}\right)$ of $\sim 3.6$ minutes, which coincides with the concomitant decreasing intensity of IR peaks at 1957 and $1946 \mathrm{~cm}^{-1}\left(t_{1 / 2}\right.$ avg $5.4 \mathrm{~min}$, Fig. S9 $\dagger$ ), we attribute the

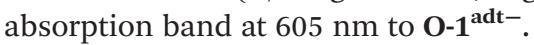

The instability of $\mathbf{0 - 1} \mathbf{1}^{\text {adt- }}$ has so far precluded its characterization by X-ray crystallography. Nevertheless, the mass spectrometry, EPR, UV-visible and FTIR data, in combination with

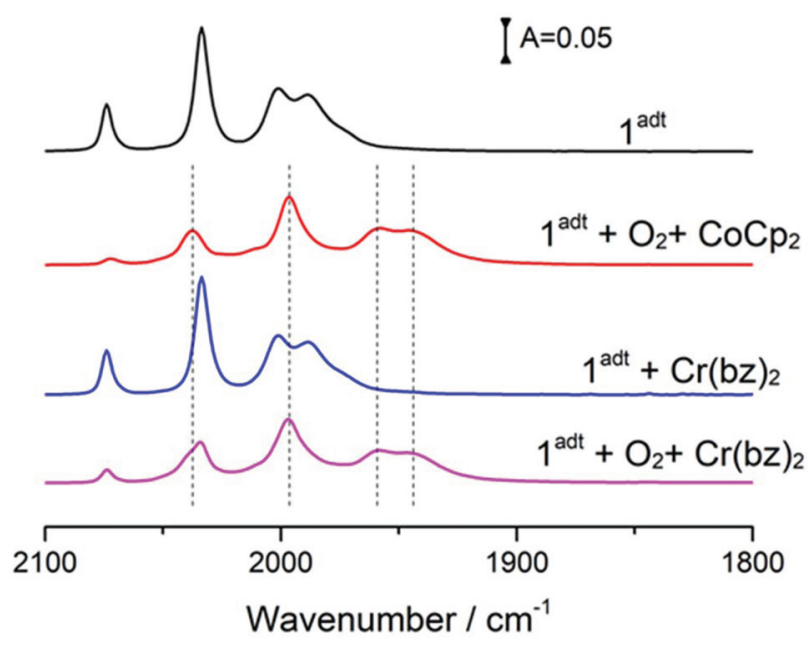

Fig. 3 The formation of a new species, $O-1^{\text {adt- }}$ by mixing $1^{\text {adt }}, \mathrm{O}_{2}$ and reductants, $\mathrm{CoCp}_{2}$ or $\mathrm{Cr}(\mathrm{bz})_{2}$. The complex $1^{\text {adt }}(0.36 \mathrm{mM})$ was first mixed with 4 eq. of $\mathrm{CoCp}_{2}$ or 2 eq. of $\mathrm{Cr}(\mathrm{bz})_{2}$ and then 4 eq. of $\mathrm{O}_{2}$ from $\mathrm{O}_{2}$-saturated DCM solution was added. 


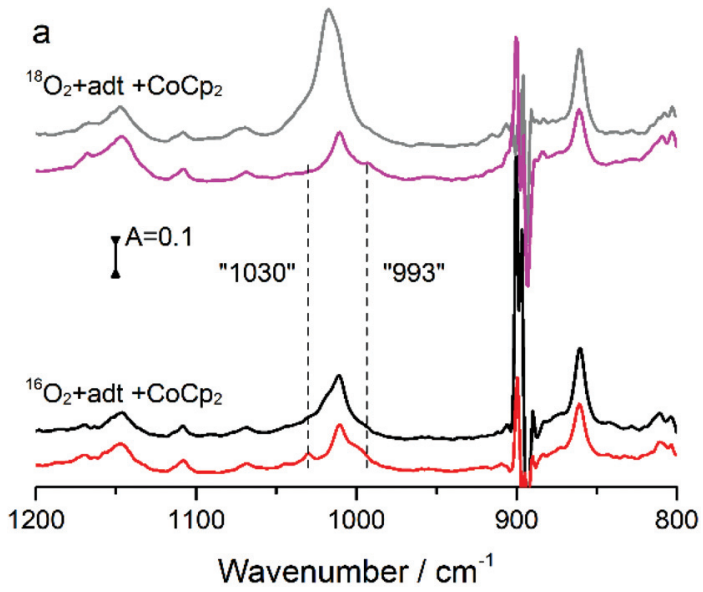

b

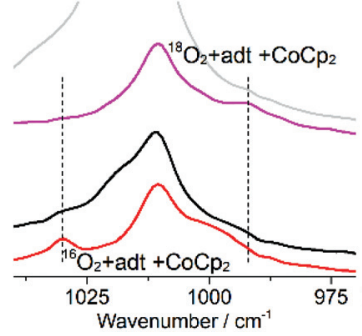

C

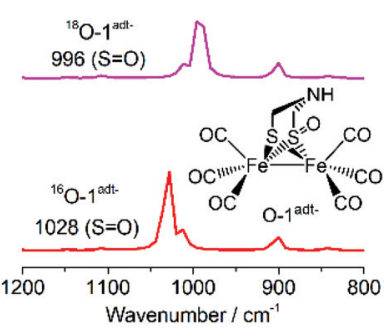

Fig. 4 (a) The IR spectra of $\nu_{\mathrm{S}}=\mathrm{O}$ from isotope ${ }^{18} \mathrm{O}_{2}$ vs. ${ }^{16} \mathrm{O}_{2}$ experiments. A mixture of $1^{\text {adt }}(4.44 \mathrm{mM})$ and 5 eq. of $\mathrm{CoCp}_{2}$ reacted with ${ }^{18} \mathrm{O}_{2}$ and ${ }^{16} \mathrm{O}_{2}$ respectively. The IR spectra were collected at $1 \mathrm{~min}$ (magenta and red traces) and 25 min (grey and black traces) after addition of $\mathrm{O}_{2}$, respectively. (b) Zoom of the IR peak region for $\nu_{S}=0$. (c) Comparison of the $\nu_{S}=0$ peak from experiments with that from DFT calculations based on the structure shown in the figure.

the DFT calculations allow us to converge on a structural model for $\mathbf{O}-\mathbf{1}^{\text {adt- }}$. First, the $\mu$-oxo diiron $\left(\mathrm{Fe}^{\mathrm{II}} \mathrm{Fe}^{\mathrm{II}}\right)$, end-on peroxide diiron $\left(\mathrm{Fe}^{\mathrm{II}} \mathrm{Fe}^{\mathrm{II}}\right)$ and bis $\left(\mu\right.$-oxo) diiron $\left(\mathrm{Fe}^{\mathrm{III}} \mathrm{Fe}^{\mathrm{III}}\right)$ species can be ruled out due to the observed red shift of the IR spectrum. Moreover, the observed EPR signal underscores that the formed product, $\mathbf{O}-\mathbf{1}^{\text {adt- }}$, is paramagnetic. Three low valent $\left(\mathrm{Fe}^{\mathrm{I}} \mathrm{Fe}^{0}\right)$ and oxygenated species were further examined: ligandbased oxygenation at the bridgehead $\mathrm{N}$ atom or the thiolate $\mathrm{S}$ atom, or metal-based oxygenation producing a $\mu$-oxo diiron state. For the first postulated structure, geometry optimization by DFT calculation methods could not be made to converge. For the low valent $\mu$-oxo diiron state, the simulated IR spectrum based on DFT calculations revealed five $\nu_{\mathrm{CO}}$ bands, in contrast with experimental results (Fig. S20†). In addition, no peaks between 1200 and $800 \mathrm{~cm}^{-1}$ were observed from the simulated IR spectrum of the $\mu$-oxo diiron $\left(\mathrm{Fe}^{\mathrm{I}} \mathrm{Fe}^{0}\right)$ state. Finally, the electron-rich $\mu$-oxo diiron $\left(\mathrm{Fe}^{\mathrm{I}} \mathrm{Fe}^{0}\right)$ center would be expected to be highly reactive at room temperature. Therefore, we assign $\mathbf{0 - 1}{ }^{\text {adt- }}$ to a $\mathrm{Fe}^{\mathrm{I}} \mathrm{Fe}^{0}$ species with a retained $\mathrm{Fe}_{2}(\mathrm{CO})_{6}$ core and an oxygenated ligand derived S-atom (Scheme 1). Indeed, the IR-spectrum for this species is in good agreement with the vibrational spectrum obtained from DFT calculations (Fig. 4 and Fig. S19-20†), and all aforementioned spectrometry and spectroscopic analysis.

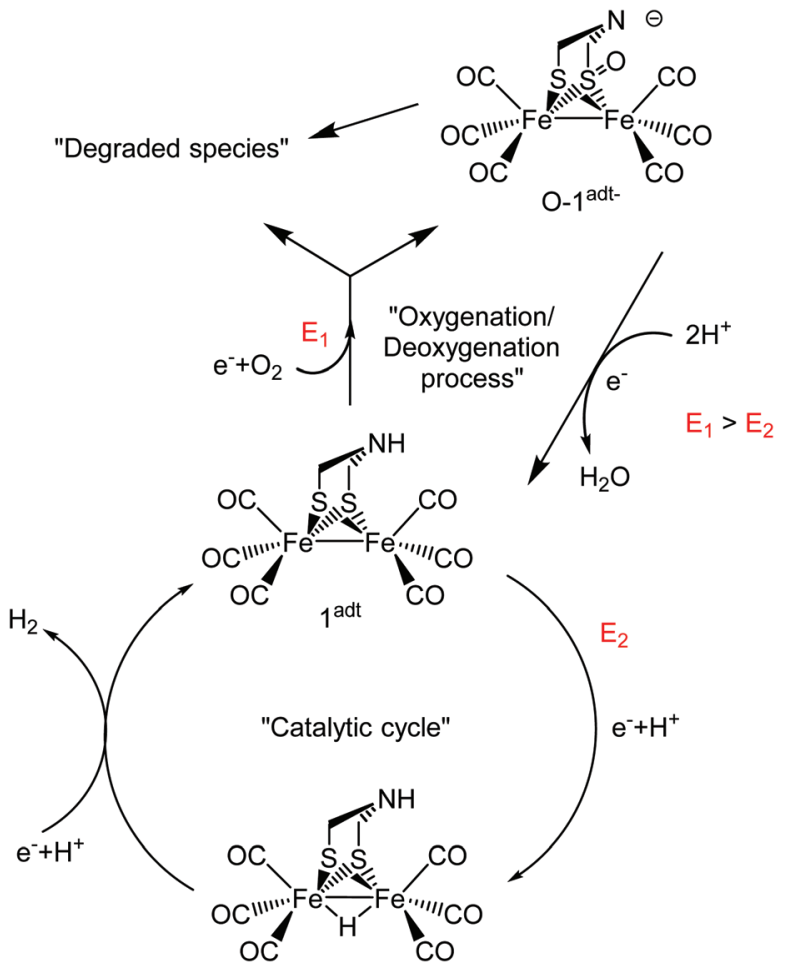

Scheme 1 Summary of the mechanism for oxygenation/deoxygenation processes and the catalytic cycle for $\mathrm{H}_{2}$ evolution catalyzed by $1^{\text {adt }}$. The red character, $\mathrm{E}$ is the reduction potential.

\section{Reactivity towards O-atom transfer reagents}

As described above, the reaction of mCPBA with $2^{\text {pdt }}$ generates $\mathbf{0 - 2} \mathbf{p}^{\text {pdt }}$ via an oxygen atom transfer reaction, which allowed us to explore whether the formation of $\mathbf{O - 1}{ }^{\text {adt- }}$ or $\mathbf{O}-2^{\text {pdt- }}$ could be achieved via such oxygenated intermediates. The formation of $\mathbf{O}-2^{\text {pdt }}$ proceeded smoothly upon mixing $2^{\text {pdt }}$ with 2 eq. of mCPBA (Fig. S12 $\dagger$ ). ${ }^{17}$ In contrast, no new peaks in the CO region were observed when treating $\mathbf{1}^{\text {adt }}$ with 2 eq. of mCPBA, and larger excess of mCPBA led to diminishing $\nu_{\mathrm{CO}}$ peaks from $\mathbf{1}^{\text {adt }}$, with concomitant appearance of only two weak peaks at 2082 and $2040 \mathrm{~cm}^{-1}$ (Fig. S12 $\dagger$ ). The new peaks remained after 1-hour incubation for both reactions. In addition, no apparent change in $\nu_{\mathrm{CO}}$ peaks was observed when adding $\mathrm{CoCp}_{2}$ into a mixture of $2^{\text {pdt }}$ (or $\mathbf{1}^{\text {adt }}$ ) and mCPBA. This is attributable to the lower reduction potential for $\mathbf{0 - 2} \mathbf{p}^{\mathbf{p d t}},-1.58 \mathrm{~V}^{17}$ Thus, the preparation of $\mathbf{0 - 1} \mathbf{1}^{\text {adt }}$ or $\mathbf{O}-2^{\text {pdt }}$ by mCPBA do not appear to be intermediate species during the formation of the reduced oxygenated species $\left(\mathbf{O}-\mathbf{1}^{\text {adt- }}, \mathbf{O}-2^{\text {pdt- }}\right)$ reported here.

\section{The role of ROS}

We further examined whether these oxygenated adducts can be prepared through ROS generated from reacting $\mathrm{CoCp}_{2}$ with $\mathrm{O}_{2}$. In addition, the reactivity of ROS with these reduced and oxygenated adducts was studied as well. The reaction of $\mathrm{O}_{2}{ }^{--}$ with $1^{\text {adt }}$ and $2^{\text {pdt }}$ respectively, resulted in the appearance of a broad shoulder band between $1980 \mathrm{~cm}^{-1}$ and $1900 \mathrm{~cm}^{-1}$ in both cases (Fig. S13†). The newly formed peaks remained for 
20 hours, in contrast to the reversible formation of $\mathbf{0 - 1} \mathbf{a d t}^{\text {adt }}$. Thus, superoxide is highly unlikely to be involved in the formation of $\mathbf{0 - 1}{ }^{\text {adt }-}$. Furthermore, no new peaks were observed when mixing $\mathrm{H}_{2} \mathrm{O}_{2}$ with $\mathbf{1}^{\text {adt }}$ and $2^{\text {pdt }}$ respectively, which is similar with the earlier report. ${ }^{6}$ However, the $\nu_{\mathrm{CO}}$ peaks for O-2 ${ }^{\text {pdt- }}$ diminished after mixing $\mathrm{H}_{2} \mathrm{O}_{2}$ with $\mathbf{O}-2^{\text {pdt- }}$, while no apparent decrease in $\nu_{\mathrm{CO}}$ absorption was observed for $\mathbf{0}-\mathbf{1}^{\text {adt- }}$ after mixing with $\mathrm{H}_{2} \mathrm{O}_{2}$ (Fig. S14 $\dagger$ ). Critically, the formation of O-1 ${ }^{\text {adt- }}$ was also observed using the reducing agent, $\mathrm{Cr}(\mathrm{bz})_{2}$ which has a more positive reduction potential $(\sim 0.12 \mathrm{~V}$, Table $\mathrm{S} 1 \dagger$ ) than the $\mathrm{O}_{2} / \mathrm{O}_{2}{ }^{--}$couple (Fig. 3). In combination, these results suggest that ROS is highly unlikely to be involved in the formation of neither $\mathbf{O}-\mathbf{1}^{\text {adt- }}$ nor $\mathbf{O}-\mathbf{2}^{\text {pdt- }}$.

\section{Reactivity of $0-1^{\text {adt- }}$}

Incubation of $\mathbf{0 - 1} \mathbf{1}^{\text {adt- }}$ under a glovebox atmosphere for 20 hours at room temperature, resulted in recovery of approximately $30 \%$ of $\mathbf{1}^{\text {adt }}$ (Fig. 5). Multiple new high-wavenumber bands were observed during the deoxygenation process from O-1 ${ }^{\text {adt- }}$ to $\mathbf{1}^{\text {adt }}$, indicating the formation of intermediate species during the reaction (Fig. S9†). Additionally, the distinct IR peaks for $\mathrm{H}_{2} \mathrm{O}$ accumulated during deoxygenation (Fig. S10†). The $\mathbf{O}-\mathbf{1}^{\text {adt- }}$ species could subsequently be regenerated by addition of fresh cobaltocene and $\mathrm{O}_{2}$ as shown in Fig. 5. In comparison, much lower amount of reformed $\mathbf{1}^{\text {adt }}(<5 \%)$ was observed when $\mathbf{0 - 1} \mathbf{1}^{\text {adt- }}$ samples were placed at ambient conditions, while samples were stable for 20 hours inside the glovebox at $-30^{\circ} \mathrm{C}$ (Fig. S11†).

\section{The role of protons}

The reactivity of $\mathbf{O}-\mathbf{1}^{\text {adt- }}$ and $\mathbf{O}-\mathbf{2}^{\text {pdt- }}$ towards protons was further probed with two acids, chloroacetic acid $\left(\mathrm{p} K_{\mathrm{a}}=18.8\right.$ in

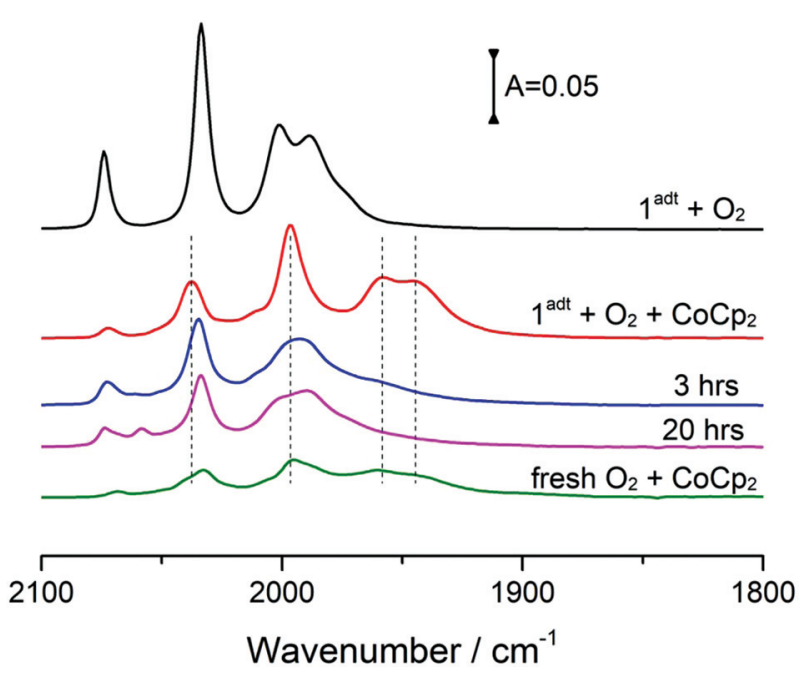

Fig. 5 The stability and reversibility of $0-1^{\text {adt- }}$ at room temperature. Samples were prepared and stored in the glovebox at room temperature and covered with tin foil to prevent photodissociation. Red line: mix 4 eq. of $\mathrm{CoCp}_{2}$ and 1 eq. of $1^{\text {adt }}(0.36 \mathrm{mM})$ with 4 eq. of $\mathrm{O}_{2}$. Blue line: 3 hours after mixing. Magenta line: 20 hours after mixing. Olive line: addition of 10 eq. fresh $\mathrm{CoCp}_{2}$ and $\mathrm{O}_{2}$ to re-generate $1^{\text {adt }}$ to $0-1^{\text {adt- }}$.

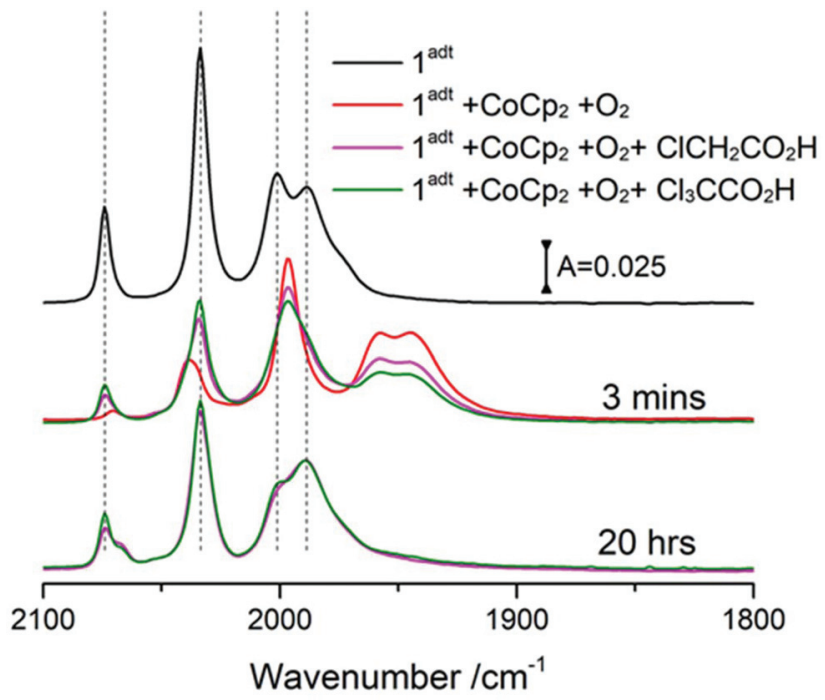

Fig. 6 The reactivity of acids with $0-1^{\text {adt- }}$. A solution with four equivalents of $\mathrm{CoCp}_{2}$ and an equivalent of $1^{\text {adt }}$ was mixed with four equivalents of $\mathrm{O}_{2}$ (red line). Then two equivalents of acid against the starting concentration of $1^{\text {adt }}(0.36 \mathrm{mM})$, chloroacetic acid (magenta color) and trichloroacetic acid (olive color), were added later respectively. The samples were stored in the glovebox at room temperature.

acetonitrile) and trichloroacetic acid $\left(\mathrm{p} K_{\mathrm{a}}=10.7\right.$ in acetonitrile) ${ }^{18}$ both of which have been used as proton source in electrocatalytic $\mathrm{H}_{2}$ evolution studies with the two complexes. $^{2,7,9}$ It has been suggested that the bridgehead $\mathrm{N}$ atom of $\mathbf{1}^{\text {adt }}$ can be protonated by trichloroacetic acid but not chloroacetic acid. ${ }^{9}$ The reformed $\mathbf{1}^{\text {adt }}$ species was observed rapidly upon the addition of either of the acids with $\mathbf{O - 1} \mathbf{1}^{\text {adt- }}$, as shown in Fig. 6. Compared to reformation of $\mathbf{1}^{\text {adt }}$ in the absence of acids, the deoxygenation process is faster and the yield is higher in the presence of acids ( $c a$. 60\% recovery vs. $30 \%$ in the absence of acids). Similarly, the conversion from $\mathbf{O}-2^{\text {pdt- }}$ to $2^{\text {pdt }}$ was also accelerated under acidic conditions (Fig. S15 $\dagger$ ). Thus, in both cases, the addition of protons facilitates the deoxygenation process and prevents further damage at room temperature. As opposed to the clear effect of acid, no apparent increase in the amount of regenerated $\mathbf{1}^{\text {adt }}$ was observed by adding excess of reduced $\mathrm{CoCp}_{2}$ to facilitate the deoxygenation process (i.e. electron source) (Fig. S16†).

\section{Discussion}

Herein, the one-electron reduced and oxygenated species, $\mathbf{O}-\mathbf{1}^{\text {adt- }}$ and $\mathbf{0}-\mathbf{2}^{\text {pdt- }}$, were prepared and investigated. Recent studies by Dey, Darensbourg and co-workers have shown that similar analogues of $\mathbf{1}^{\text {adt }}$ and $2^{\text {pdt }}$ attached on the electrode surface are capable of catalyzing the $\mathrm{O}_{2}$ reduction reaction (ORR) in aqueous solution, albeit with gradual degradation during electrochemical catalysis. ${ }^{5,6}$ Noticeably, the onset current for $\mathrm{O}_{2}$ reduction was observed more positive $(\sim 0.1 \mathrm{~V})$ than the first reduction potential of the studied $\mathbf{1}^{\text {adt }}$ analogues, which suggests that electron transfer can occur at the more 
positive potential through coupling chemical steps. This observation is firmly supported by the formation of $\mathbf{O}-\mathbf{1}^{\text {adt- }}$ through chemical reductants in the presence of molecular oxygen reported here. Since the reduction potential for $\mathrm{Fe}^{\mathrm{I}} \mathrm{Fe}^{\mathrm{I}}$ to $\mathrm{Fe}^{\mathrm{I}} \mathrm{Fe}^{0}$ is significantly more negative $(\sim c a .0 .4 \mathrm{~V})$ than the reduction potential of the mildest reductant, $\mathrm{Cr}(\mathrm{bz})_{2}$, it is highly unlikely that reduction chemistry occurs prior to the oxygenation reaction (i.e. the chemical step). Instead, the most likely scenario is that a pre-equilibrium exists with reversible binding of $\mathrm{O}_{2}$ to $\mathbf{1}^{\text {adt }}$ or $2^{\text {pdt }}$ before reduction chemistry takes place, although the association constant for the complex, $\left[\mathrm{O}_{2} \cdots 1^{\text {adt }}\right]$ or $\left[\mathrm{O}_{2} \cdots 2^{\mathrm{pdt}}\right]$, must be very small. The formation of a complex of $\left[\mathrm{O}_{2} \cdots 1^{\text {adt }}\right]$ or $\left[\mathrm{O}_{2} \cdots 2^{\text {pdt }}\right]$ provides an anodic shift of the reduction potential of the diiron center and facilitates sequential redox and oxygenation reactions.

Although the bridgehead atoms are different (i.e. $\mathrm{N} v$ s. C), the two diiron center complexes, $\mathbf{1}^{\text {adt }}$ and $\mathbf{2}^{\text {pdt }}$, have a similar electronic structure. Still, the protonatable aza group in the second coordination sphere in this family of complexes generally improves their catalytic properties. Analogously, their reactivity with $\mathrm{O}_{2}$ in the presence of reductants led to different oxygenated structures and the reactivity of $2^{\text {pdt }}$ was more sluggish. Noticeably, the oxygenated $2^{\text {pdt }}$ complex has more $\nu_{\mathrm{CO}}$ peaks than the four distinct peaks observed for $\mathbf{0}-\mathbf{1}^{\text {adt- }}$, suggesting the formation of multiple products. When mCPBA was used as the oxygen donor, the oxygenated, non-reduced, adduct of $2^{\text {pdt }}$ was formed, whereas $\mathbf{1}^{\text {adt }}$ was much less reactive and did not form the corresponding complex. Thus, the present results suggest that the second coordination sphere also modulates the reactivity of oxygenation. However, upon addition of protons, no apparent differences between these complexes were observed in the deoxygenation process. Both $\mathbf{1}^{\text {adt }}$ and $2^{\text {pdt }}$ were rapidly regenerated after addition of acids. Water was observed as the product during the deoxygenation process of O-1 ${ }^{\text {adt- }}$ and attempts to detect $\mathrm{H}_{2} \mathrm{O}_{2}$ via three various methods were not successful. Based on the oxygenation/deoxygenation processes of $\mathbf{1}^{\text {adt }}$ discovered here and the mechanism for $\mathrm{H}_{2}$ evolution suggested by earlier studies, ${ }^{2,9,15}$ a schematic catalytic cycle of $\mathbf{1}^{\text {adt }}$ for $\mathrm{H}_{2}$ evolution in the presence of molecular oxygen is summarized in Scheme 1.

As pointed out in the introduction, the formation of ROS, expected to irreversibly damage the catalyst, is thermodynamically more favorable than proton reduction. Nevertheless, examples where proton reduction occurs under ambient conditions, have been reported. In nature, $\left[\mathrm{Fe}_{4} \mathrm{~S}_{3}\right]$-containing [NiFe] hydrogenases have been shown to catalyze $\mathrm{H}_{2}$ oxidation in the presence of $\mathrm{O}_{2}$. The oxygen-tolerant property from this subset of hydrogenases is generally ascribed to the unique $\left[\mathrm{Fe}_{4} \mathrm{~S}_{3}\right]$ cluster that accommodates three oxidation states and acts as electron reservoirs for the reduction of $\mathrm{O}_{2}$ to harmless water instead of the formation of ROS. ${ }^{19,20}$ Therefore, one way to prevent such oxygen-induced damage is to develop bifunctional catalysts that can catalyze ORR to water. Cobalt diimine-dioxime, one of few known oxygen-tolerant $\mathrm{H}_{2}$-evolving catalysts, demonstrates this bifunctionality. ${ }^{21}$ Here, we show that $\mathbf{1}^{\text {adt }}$ can react reversibly with $\mathrm{O}_{2}$ in the pres- ence of reductants and previous electrochemical results from similar complexes also revealed the capacity for ORR chemistry albeit with limited stability during electrocatalysis. Further improvement of these diiron thiolate complexes are expected to enhance their stability during ORR and thus decrease oxygen sensitivity. Indeed, very recently, it was reported that the ORR and oxygen-tolerance of $\mathbf{1}^{\text {adt }}$ can be greatly improved via substitutions of the N-bridgehead atom, resulting in improving proton shuttling. ${ }^{22}$

Specifically with regards to [FeFe] hydrogenases, several $\mathrm{O}_{2}$ inactivated structures have been reported, many of which are considered to result in irreversible inactivation. ${ }^{23,24}$ For example, the oxygenation of sulfur at cysteine 169 (i.e. the formation of sulfenic acid) near the diiron center was observed after $\mathrm{O}_{2}$ exposure to [FeFe] hydrogenases from C. reinhardtii. However, Léger, Blumberger and co-workers have suggested that the reaction between $\mathrm{O}_{2}$ and $[\mathrm{FeFe}]$ hydrogenases is a multi-step process. The initial species formed upon exposure to $\mathrm{O}_{2}$ can be either reactivated, i.e. suggesting a reversible deoxygenation process, or further proceed to yield an irreversibly inactivated dead-end species. ${ }^{25,26}$ Here, we provide chemical precedence for such a direct oxygenation processes of the thiolate $\mathrm{S}$ atom via molecular oxygen, as well as the reversible deoxygenation process and degradation of oxygenated $\mathbf{1}^{\text {adt }}$. Considering the structural similarities between $\mathbf{1}^{\text {adt }}$ and the $\mathrm{H}$-cluster, this reactivity may also be relevant to [FeFe] hydrogenase.

\section{Conclusions}

In summary, this study reports on the oxygenation of two low valent diiron complexes, mimicking the $[\mathrm{FeFe}]$ hydrogenase cofactor, under reducing conditions. The preparation of $\mathbf{O}-\mathbf{1}^{\text {adt- }}$ and $\mathbf{O}-2^{\text {pdt- }}$ provides a new venue for exploring the reactivity between molecular oxygen and $\mathrm{H}_{2}$-evolving catalysts. The results presented herein underscore the influence of the bridgehead nitrogen in the reaction towards $\mathrm{O}_{2}$, and the importance of protons for the reversibility of the process. Insights learned from studying these systems are expected to provide new guidelines for the design of oxygen-tolerant catalysts for $\mathrm{H}_{2}$ evolution and the engineering of [FeFe] hydrogenases. Detailed investigations of the oxygenation and deoxygenation mechanisms of these two complexes at low temperature conditions are currently ongoing.

\section{Experimental methods}

\section{Chemicals}

Bis(cyclopentadienyl)cobalt(II), bis(pentamethylcyclopentadienyl)cobalt(II), potassium superoxide, hydrogen peroxide $(30 \% \mathrm{w} / \mathrm{w}$ in water) and ${ }^{18} \mathrm{O}_{2}(97 \%)$ were purchased from Sigma-Aldrich. Chloroacetic acid (>99.0\%), trichloroacetic acid (>99.0\%) and 3-chloroperbenzoic acid (mCPBA) were also obtained from Sigma-Aldrich. The molecular oxygen (99.9\%) from Air Liquide 
was used for this study. Bis(benzene)chromium was purchased from Alfa Aesar.

\section{Precursor to $1^{\text {adt }}$}

The synthesis of the precursor to $\mathbf{1}^{\text {adt }}, \mathrm{Fe}_{2}(\mu-\mathrm{S})_{2}(\mathrm{CO})_{6}$ was adapted from literature procedures. ${ }^{27}$ A $500 \mathrm{~mL}$ three-necked round-bottom flask was equipped with a mechanical stirrer and a bubbler. To this was added iron(0) pentacarbonyl (6.3 mL, $47.9 \mathrm{mmol})$. Degassed methanol $(32 \mathrm{~mL})$ was added to the reaction vessel, followed by a freshly prepared and degassed $50 \mathrm{wt} \%$ aqueous solution of potassium hydroxide $(20 \mathrm{~mL})$. The reaction mixture was stirred for 30 minutes and then cooled to $0{ }^{\circ} \mathrm{C}$. Sulfur $(8.1663 \mathrm{~g}, 0.25 \mathrm{~mol})$ was added to the reaction mixture over the course of 5 minutes. This mixture was stirred for one hour at $0{ }^{\circ} \mathrm{C}$. Degassed water $(60 \mathrm{~mL})$ and degassed pentane $(180 \mathrm{~mL})$ was added to the reaction vessel. Ammonium chloride (21.8366 g, $0.41 \mathrm{~mol}$ ) was added to the reaction mixture very slowly and in portions because the reaction produces lots of hydrogen sulfide gas. The reaction vessel was allowed to warm to room temperature, and stirred for 16 hours. After 16 hours, the reaction could be seen to form two layers, one black sticky aqueous phase, and a deep red pentane phase. The reaction mixture was passed through a $100 \mathrm{~mL}$ pad of Celite and washed with pentane until the black precipitate collected in the flask appeared slightly grey. The organic fraction was split into smaller volumes of $300 \mathrm{~mL}$ and washed with equal volumes of water. The organic phases were then dried over magnesium sulfate, filtered and pentane was evaporated under reduced pressure. The crude product was recombined and re-dissolved in a small volume of pentane before passing it through a silica column with pentane eluent. The solvent was removed under reduced pressure to produce a brown solid $\left(\mathrm{Fe}_{2}(\mu-\mathrm{s})_{2}(\mathrm{CO})_{6}, 2.7625 \mathrm{~g}\right.$, 8.03 mmol, 16\% yield). FTIR (MeCN) 2002, 2041, and $2083 \mathrm{~cm}^{-1}$.

\section{Synthesis of $1^{\text {adt }}$ and $2^{\text {pdt }}$}

The synthesis of $\mathbf{1}^{\text {adt }}$ and $2^{\text {pdt }}$ followed literature procedures. ${ }^{28,29}$

\section{Reactions of $1^{\text {adt }}$ and $2^{\text {pdt }}$ with molecular oxygen in the pres- ence of reductants}

All chemical solvent (mainly, dichloromethane) used in this study were obtained from solvent stills. Oxygen-free DCM was prepared by at least four freeze-pump-thaw cycles. Oxygen-free DI $\mathrm{H}_{2} \mathrm{O}$ or $\mathrm{H}_{2} \mathrm{O}_{2}$ were prepared by purging with $\mathrm{N}_{2}$ for an hour. The oxygen-saturated DCM was prepared by purging $\mathrm{O}_{2}$ for an hour and the concentration of saturated oxygen in DCM is estimated to be $c a$. $9 \mathrm{mM}$ according to literature. ${ }^{30,31}$ The superoxide radicals were prepared by mixing potassium superoxide and 18-crown-6 ether (Sigma-Aldrich). All mixtures of $\mathbf{1}^{\text {adt }}$ or $2^{\text {pdt }}$ with reductants (such as $\mathrm{CoCp}_{2}$, $\mathrm{CoCp}_{2}{ }^{*}$ and $\mathrm{Cr}(\mathrm{Bz})_{2}$ ) in DCM were prepared inside an Ar-containing glovebox $(0.5 \mathrm{ppm}$ $<\mathrm{O}_{2}$ and $0.5 \mathrm{ppm}<\mathrm{H}_{2} \mathrm{O}$ ). Molecular oxygen was either introduced from the oxygen-saturated DCM inside the glovebox or directly added excessive $\mathrm{O}_{2}$ into a sealed vial containing a mixture of $1^{\text {adt }}$ or $2^{\text {pdt }}$ and reductants outside the glove box.
When reacting with superoxide, hydrogen peroxide and mCPBA, all experiments were conducted inside the glovebox. When samples were stored inside the glovebox, the sample vial was wrapped with tin foil to prevent photodissociation.

\section{Spectroscopic characterization}

Nuclear magnet resonance measurements were recorded with a JEOL (400 YH magnet) Resonance $400 \mathrm{MHz}$. Infrared spectrum was collected with a Bruker IFS 66 v/S FT-IR spectrometer, in which the DLaTGS detector was employed with $2 \mathrm{~cm}^{-1}$ resolution. Sample solution was prepared inside a gastight IR cell with $\mathrm{CaF}_{2}$ or $\mathrm{KBr}$ as windows. For UV-visible spectrum, the Carry 5000 spectrometer was used and the sample solution was placed in a gas-tight UV-visible cuvette. The mass spectrum was collected in a negative mode with a Thermo Finnigan LCQ Deca XP Max LC/MS spectrometer through the direct injection mode. EPR spectra were recorded at X-band at 9.28 $\mathrm{GHz}$, modulation frequency $100 \mathrm{kHz}$ and modulation amplitude 5 Gauss on a Bruker ELEXYS E500 using an ER049X SuperX microwave bridge in a Bruker SHQ0601 cavity equipped with an Oxford Instruments continuous flow cryostat and an ITC 503 temperature controller (Oxford Instruments). A $1 \mathrm{mM}$ $\mathrm{CuSO}_{4}$ and 10 eq. of EDTA dissolved in water was employed as a standard sample for spin counting.

\section{DFT calculation methods}

The computational methods were followed as the previous reports. ${ }^{32,33}$ In brief, DFT calculations were conducted with the Gaussian 97 package using BP86 functionals with the Def2TZVP basis set $^{32}$ or cc-pVDZ/cc-pVTZ/SDD basis set. ${ }^{33}$ Both basis sets were used to calculate similar molecular systems before. All geometry-optimized structures obtained in the gas phase were further optimized with the SMD solvation model for DCM solvent. The final optimized structure was used to simulate IR spectra. Compared to experimental IR spectra, both basis sets yielded the same trends for all simulated molecular complexes based on $\mathbf{1}^{\text {adt }}$ or $2^{\text {pdt }}$ structure but the Def2TZVP basis set resulted in the less deviation of the absorption of carbonyl groups from $\mathbf{1}^{\text {adt }}$ and $2^{\text {pdt }}$. Here, only results from the method (BP86 functionals and Def2TZVP basis) are shown.

\section{Conflicts of interest}

There are no conflicts to declare.

\section{Acknowledgements}

This work was financially supported by the Swedish research Council (contract no. 621-2014-5670) and ERC (contract no. 714102 , to G. B.). We acknowledge postdoc grants to V. W. and C. E. from the Wenner-Gren Foundations. We are very grateful to Jakob Thyr and Prof. Tomas Edvinsson, who made initial efforts on Raman spectroscopy and provided inspiration on IR 
measurements. We also thank Dr Patrícia Raleiras for conducting spin counting experiments and MSc. Robin Tyburski for supporting DFT calculations through his funding.

\section{References}

1 D. L. DuBois, Inorg. Chem., 2014, 53, 3935-3960.

2 D. Schilter, J. M. Camara, M. T. Huynh, S. HammesSchiffer and T. B. Rauchfuss, Chem. Rev., 2016, 116, 86938749.

3 J. Y. Yang, R. M. Bullock, W. G. Dougherty, W. S. Kassel, B. Twamley, D. L. DuBois and M. R. DuBois, Dalton Trans., 2010, 39, 3001-3010.

4 D. W. Wakerley, M. A. Gross and E. Reisner, Chem. Commun., 2014, 50, 15995-15998.

5 S. Dey, A. Rana, S. G. Dey and A. Dey, ACS Catal., 2013, 3, 429-436.

6 S. Dey, A. Rana, D. Crouthers, B. Mondal, P. K. Das, M. Y. Darensbourg and A. Dey, J. Am. Chem. Soc., 2014, 136, 8847-8850.

7 D. S. Chong, I. P. Georgakaki, R. Mejia-Rodriguez, J. Samabria-Chinchilla, M. P. Soriaga and M. Y. Darensbourg, Dalton Trans., 2003, 4158-4163.

8 S. J. Borg, T. Behrsing, S. P. Best, M. Razavet, X. M. Liu and C. J. Pickett, J. Am. Chem. Soc., 2004, 126, 16988-16999.

9 M. Bourrez, R. Steinmetz and F. Gloaguen, Inorg. Chem., 2014, 53, 10667-10673.

10 D. W. Mulder, E. S. Boyd, R. Sarma, R. K. Lange, J. A. Endrizzi, J. B. Broderick and J. W. Peters, Nature, 2010, 465, 248-251.

11 J. W. Peters, W. N. Lanzilotta, B. J. Lemon and L. C. Seefeldt, Science, 1998, 282, 1853-1858.

12 A. Silakov, B. Wenk, E. Reijerse and W. Lubitz, Phys. Chem. Chem. Phys., 2009, 11, 6592-6599.

13 G. Berggren, A. Adamska, C. Lambertz, T. R. Simmons, J. Esselborn, M. Atta, S. Gambarelli, J. M. Mouesca, E. Reijerse, W. Lubitz, T. Happe, V. Artero and M. Fontecave, Nature, 2013, 499, 66-69.

14 S. Wang, S. Pullen, V. Weippert, T. Liu, S. Ott, R. Lomoth and L. Hammarström, Chem. - Eur. J., 2019, 25, 1113511140.

15 A. Aster, S. Wang, M. Mirmohades, C. Esmieu, G. Berggren, L. Hammarström and R. Lomoth, Chem. Sci., 2019, 10, 5582-5588.
16 I. A. de Carcer, A. DiPasquale, A. L. Rheingold and D. M. Heinekey, Inorg. Chem., 2006, 45, 8000-8002.

17 T. B. Liu, B. Li, M. L. Singleton, M. B. Hall and M. Y. Darensbourg, J. Am. Chem. Soc., 2009, 131, 82968307.

18 F. Eckert, I. Leito, I. Kaljurand, A. Kutt, A. Klamt and M. Diedenhofen, J. Comput. Chem., 2009, 30, 799-810.

19 P. Wulff, C. C. Day, F. Sargent and F. A. Armstrong, Proc. Natl. Acad. Sci. U. S. A., 2014, 111, 6606-6611.

20 L. Lauterbach and O. Lenz, J. Am. Chem. Soc., 2013, 135, 17897-17905.

21 N. Kaeffer, A. Morozan and V. Artero, J. Phys. Chem. B, 2015, 119, 13707-13713.

22 M. E. Ahmed, S. Dey, M. Y. Darensbourg and A. Dey, J. Am. Chem. Soc., 2018, 140, 12457-12468.

23 S. T. Stripp, G. Goldet, C. Brandmayr, O. Sanganas, K. A. Vincent, M. Haumann, F. A. Armstrong and T. Happe, Proc. Natl. Acad. Sci. U. S. A., 2009, 106, 17331-17336.

24 K. D. Swanson, M. W. Ratzloff, D. W. Mulder, J. H. Artz, S. Ghose, A. Hoffman, S. White, O. A. Zadvornyy, J. B. Broderick, B. Bothner, P. W. King and J. W. Peters, J. Am. Chem. Soc., 2015, 137, 1809-1816.

25 C. Orain, L. Saujet, C. Gauquelin, P. Soucaille, I. MeynialSalles, C. Baffert, V. Fourmond, H. Bottin and C. Leger, J. Am. Chem. Soc., 2015, 137, 12580-12587.

26 A. Kubas, C. Orain, D. De Sancho, L. Saujet, M. Sensi, C. Gauquelin, I. Meynial-Salles, P. Soucaille, H. Bottin, C. Baffert, V. Fourmond, R. B. Best, J. Blumberger and C. Leger, Nat. Chem., 2017, 9, 88-95.

27 J. L. Stanley, T. B. Rauchfuss and S. R. Wilson, Organometallics, 2007, 26, 1907-1911.

28 D. Seyferth, G. B. Womack, M. K. Gallagher, M. Cowie, B. W. Hames, J. P. Fackler and A. M. Mazany, Organometallics, 1987, 6, 283-294.

29 R. Zaffaroni, T. B. Rauchfuss, D. L. Gray, L. De Gioia and G. Zampella, J. Am. Chem. Soc., 2012, 134, 19260-19269.

30 K. Shirono, T. Morimatsu and F. Takemura, J. Chem. Eng. Data, 2008, 53, 1867-1871.

31 T. Sato, Y. Hamada, M. Sumikawa, S. Araki and H. Yamamoto, Ind. Eng. Chem. Res., 2014, 53, 19331-19337.

32 M. Mirmohades, S. Pullen, M. Stein, S. Maji, S. Ott, L. Hammarstrom and R. Lomoth, J. Am. Chem. Soc., 2014, 136, 17366-17369.

33 C. P. Liu, T. B. Liu and M. B. Hall, J. Chem. Theory Comput., 2015, 11, 205-214. 